The most satisfactory method of accomplishing this is the rotation of the wedges in their own plane, but long narrow wedges cannot be adjusted in this manner without considerable difficulty.

As a result of these investigations we have built a polariscope in which

(a) The compensating wedge is reduced to a length of $20 \mathrm{~mm}$;

(b) 'The wedges are moved by an accurate micrometer screw carrying a large drum on which the scale is engraved;

(c) The short wedges are mounted in plates which may be rotated by known amounts by means of set screws.

This wedge system has a great advantage over the old type in so far as errors due to want of homogeneity in the quartz are almost entirely eliminated, as areas of this size of the required purity can generally be found in crystal plates if sufficient care is taken. Further as the angle of the wedges is increased difficulties in the manufacture are greatly reduced so that the surface may be worked plane to $1 / 10$ of the wave-length of sodium light. These short wedges are $12 \mathrm{~mm}$. wide and may be rotated over several degrees without decreasing the aperture. In fact there is no reason why they should not be angular discs and the scale length could then be varied at will from the minimum, depending on the angle of the wedge, to infinity. We have compiled tables for giving the necessary angular rotation to the wedges to increase or decrease the total scale length by any required amount. If, for instance, the normal plate should read 0.2 high a rotation of a few minutes will be necessary to make the reduction. These adjustments can be carried out from the outside of the wedge box with the greatest ease.

BilininghaM AND STANLEX, IMMITED

London, Engl,ANd, February 27, 1919

\section{THE MOHR AND THE METRIC MILLILITER}

Editor of the Journal of Industrial and Engineering Chemistry:

A matter regarding which there is now a good deal of confusion and which badly needs standardization is that which refers to the basis of graduation of volumetric glassware. The older standard is the so-called Mohr cubic centimeter, which is the volume occupied by I $\mathrm{g}$. of water at $15^{\circ} \mathrm{C}$., weighed in air with brass weights. The cubic centimeter still widely employed in the sugar industry is, however, based on a temperature of $17^{1 / 2^{\circ}}$ instead of $15^{\circ}$. The Bureau of Standards has for some time advocated the adoption of the metric cubic centimeter, or, to be exact, the metric milliliter, which is the volume occupied by $\mathrm{I} g$. of water at $4^{\circ} \mathrm{C}$. weighed in vacuo, the standard temperature for the use of the apparatus being specified as $20^{\circ} \mathrm{C}$. The newer normal weights for saccharimeters, 26 and $20 \mathrm{~g}$., refer to a volume of roo metric milliliters at $20^{\circ} \mathrm{C}$.

Those in the sugar industry have a special reason to adopt the metric milliliter, because it simplifies the value of the normal weight, and they perhaps are as much to blame as any one for the adherence to the old standards. While the use of the metric milliliter in the sugar industry was recommended some time ago, the writer hesitated to adopt the metric milliliter for sugar flasks and still be forced to accept other kinds of volumetric apparatus graduated in Mohr cubic centimeters, as the existence of two standards for volumetric apparatus in the same laboratory would lead to worse confusion than already has previously prevailed.

It should be unnecessary in this communication to present any of the arguments in favor of the metric milliliter. The very complete tables which have been published by the Bureat of Standards eliminate any inconvenience which the calculation to working conditions may cause. Probably the reason that the Mohr cubic centimeter has lasted so long is that until recently most volumetric glassware has been imported from countries where the Mohr standard is prevalent. Now that this condition has disappeared, it is to be hoped that American chemists will unite in adopting and specifying the metric milliliter as the basis of graduation of all volumetric apparatus, and that domestic manufacturers will do their part in eliminating the Mohr cubic centimeter as rapidly as possible.

That the situation is still hopelessly confused is shown by the replies received to a recent letter of inquiry sent to three of the most prominent dealers in laboratory supplies. Two of them state that all volumetric glassware is now, unless otherwise specified, graduated on the basis of the metric milliliter, and urge its adoption. The third replies that all regular stock volumetric ware is calibrated according to the Mohr cubic centimeter, and that, on account of the fact that volumetric analysis in general is still based on this, it would be a mistake to change to the metric milliliter.

It would be a desideratum if the AMERICAN CHEMICAL SocIETy and other associations would keep this question alive through suitable committees. In the meantime let the chemists do their part in rejecting and eliminating an unfortunate and unscientific standard.

It is also to be hoped that American manufacturers will make an effort to furnish accurately graduated volumetric apparatus. It has unfortunately been too true in the past that one is almost always right in assuming all volumetric glassware to be incorrect. It is also unfortunate that so many chemists, even in analytical work demanding high accuracy, accept the manufacturer's graduations as correct and never take the trouble to verify for themselves the accuracy of such apparatus. In many cases their education is at fault, for the verification of apparatus is one of the first tasks which the student in quantitative analysis should be given, and is too often slighted or even entirely neglected.

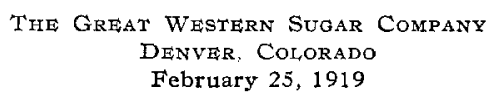

SIDNEY J. OsBorN

\section{UNIVERSITY OF VIRGINIA DEPARTMENT OF CHEMISTRY}

At the University of Virginia, the School of Analytical and Industrial Chemistry and the School of Chemistry have been merged. Its affairs will be managed by a committee of the chemical faculty.

Five new research fellowships have been established by the Board of Visitors. Applications for these should be filed with Dr. Gardner L. Carter, secretary of the chemical faculty.

\section{LIBRARIANS FOR RESEARCH LIBRARIES}

Editor of the Journal of Industrial and Engineering Chemistry:

A striking feature of the Symposium on Library Service in Industrial Laboratories, ${ }^{1}$ presented before the Industrial Division at the Victory Meeting in Buffalo, was the exclusive use of feminine pronouns in referring to librarians. Why bar the men from this complex and interesting profession?

Another equally impressive feature was that, with scarcely any exception, no mention was made of any training other than in library science for librarians of research libraries. It was tacitly assumed that the unfortunate lady (always a lady) must enter upon her duties under the handicap of entire and unillumined ignorance of the science upon which her library is based.

Why should it be so? With all respect for library science, it seems to the writer that in choosing a research librarian, primary emphasis should be on training in the library's own science and secondary emphasis on library training.

i See p. 578 , this issue. 
Discussion of this subject would be both interesting and helpful. We would like to be favored with the viewpoints of other libraries and librarians. JULIAN F. SMITH

National ANILINe and Chemical Co., INC. BuFFaLO, N..Y., Aptil 11, 1919

\section{JOHNS HOPKINS UNIVERSITY GRAFLIN SCHOLARSHIP AND RESEARCH ASSISTANTSHIPS}

Throttgh the generosity of the late Mr. Wm. H. Graflin, of Baltimore, a scholarship, to be known as the Graflin Scholarship, and three assistantships, have been established in the department of chemistry of the Johns Hopkins University.

The Graflin Scholarship will be awarded annually to a candi- date having a training equivalent to that leading to the Ph.D. degree and who therefore has had experience in research. It may be awarded twice to the same candidate. The holder of the scholarship will receive $\$$ Iooo a year and will be expected to devote his entire time to research.

The three research assistantships each pay $\$ 750$ a year and are open to chemists having the equivalent of a Ph.D. degree. The holder of a research assistantship will not be required to do any formal teaching but will be given the opportunity to devote his entire time to research and to assist in the direction of research.

Applications for the above positions for the year r919-1920 should be sent to the department of chemistry, Johns Hopkins University, 32 I. Druid Hill Avenue, Baltimore, Md., before August I.

\section{WASHINGTON LETTER}

By PAUL WootoN, Union Trust Building, Washington, D. C.

Recommendations, as to what German dyestuffs may be imported to advantage to the nation, are to be made by an advisory committee to be appointed by the War Trade. Board. In addition, the advisory committee will make recommenda tions as to means which will insure equitable distribution of such dyes as are imported and will prevent speculation and hoarding. The advisory committee is to consist of eight members, four of whom will represent producers and four, consumers.

In the so-called Brussels declaration made to Germany it was provided that Germany would be allowed to export various commodities to any country. That is, there was no objection to such exportation from Germany on blockade grounds. No individual country, however, was under obligation to receive any such goods. That made it necessary for the War Trade Board to determine a policy on dyestuffs. The "Trading with the Enemy" Act prohibits such imports except under license. The licensing power was placed in the hands of the President. He in turn delegated it to the War Trade Board.

The War Trade Board has refused consistently to use any of its powers for tariff purposes. Its concern has been with the national defense and with matters which clearly were of benefit to the nation. Great care has been taken not to encroach upon the jurisdiction of Congress.

Since it is evident that certain dyes should be allowed to come into the country, it was recognized that the matter of their distribution offered an intricate problem. Even of the much needed products, the imports will be greatly restricted. If hoarding and speculation are avoided and proper distribution assured, it will be necessary that they be imported under a guarantee. The precise form of the guarantee has not been worked out at this writing. The War Trade Board has requested the Chemical Foundation, Inc., to act as consignee for all German dyes.

Thus steps have been taken to meet the situation until the new Congress cant provide such statutory safeguards as it may feel inclined to extend to the dye industry. There seems to be little difference of opinion, however, between Democrats and Republicans with regard to the recessity of maintaining in this country a permanent dye industry. One of the difficulties which is giving members of the Ways and Means Committee concern is the fact that some of the dyes would require a duty of 300 to 400 per cent in order to grant them the protection needed. Some are hopeful that a licensing plan will be worked out. It is known that $\mathrm{Mr}$. Joseph $\mathrm{H}$. Choate, Jr., now is engaged in drafting a bill which will provide a licensing arrangement. The Tariff Commission, however, is understood to be rather dubious as to the practicability of any licensing plan. Representative Nicholas Longworth, of Ohio, who does not believe it likely that any general tariff revision will be attempted at this session of Congress, but who is very anxious that essential war-born industries should be safeguarded, expressed the following opinions to the correspondent of the Journal of Industrial and Engineering Chemistry:

Immediate protection should be extended to the dye industry in which some $\$ 300,000,000$ have been expended since the beginning of the war. This mammoth activity soon would be helpless without legislative assistance.

Generally speaking, we ought not to be dependent on any other country for necessities. This applies with special force to all coal-tar products.
Just how to handle the coal-tar product sistuation must be threshed out. In an industry so young there is no definite basis as to costs. The difficulty of tariff legislation, where costs are so different, is that the granting of reasonable protecting duties would, in some cases, have to be 300 or 400 per cent. A licensing system presents numerous administrative difficulties. It probably is wise to introduce the bill recommended by the Tariff Commission. The fact that the textile manufacturers will no longer oppose duties on dyes will make it much easier to enact proper legislation of that character.

Democratic members of the Ways and Means Committee apparently agree that tariff protection must be extended to the coal tar and other industries in the same situation, but they fear that advantage will be taken of the situation to foist higher duties on the country than are necessary to prevent the dumping of European accumulation. For that reason they expect to go into the matter very carefully but are willing that temporary safeguards. be provided in the interim.

Representative Fordney, of Michigan, who announced in March that he would be satisfied with nothing less than general tariff revision at the coming session, has not returned to Washington at this writing, but it is regarded as probable that he will not insist upon such a course in view of the prevailing sentiment against it

The United States Tariff Commission expects to have ready to place in the hands of Congress shortly after it convenes the r 9 8 dyestuff census.

Recognizing that there is much uncertainty as to the status of stills or worms adapted to the production of distilled spirits, the Commissioner of Internal Revenue has promulgated a statement covering the use, manufacture, and sale of stills. The statement is as follows:

Under federal laws and regulations manufacturers of stills are required to pay an annual special tax of $\$ 50$, and in addition thereto $\$ 20$ for each still or worm for distilling made by them. All persons, firms, or corporations thus manufacturing a still or worm to be used in distilling are deemed manufacturers of stills. This applies to all stills capable of the production of distilled spirits, but does not apply to small laboratory stills (usually glass) for legitimate laboratory purposes, or to water stills which are not capable of and intended for the production of distilled spirits. Ordinarily, laboratory stills are small, constructed of glass, and not adapted to the production of distilled spirits in commercial quantities, and many water stills are also of such construction that they are not adapted to the commercial production of distilled spirits.

Any stills or worms adapted to the production of distilled spirits for commercial or beverage purposes are presumed to be intended for such use, and in consequence the manufacture thereof involves the manufacturer in special tax liabilities as above. In order to remove such presumption in the case of stills and worms intended to be used in the manufacture of essential oils, vinegar, and lie products, and in purification of water (other than small glass laboratory stills), the person for whom such still is made will be required to submit to the Collector evidence under oath showing that the still is not to be used for the production of spirits and setting forth specifically the actual purposes for which it is to be used.

The manufacturer of any still, boiler, or any vessel to be used for the purpose of distilling must, before the same is removed 